\title{
Distortion Product Otoacoustic Emissions (DPOAEs) In Tinnitus Patients
}

\author{
Hend F. Alshabory ${ }^{1}$ Takwa A. Gabr ${ }^{1}$ Mona A. Kotait ${ }^{2}$ \\ ${ }^{1}$ Audiovestibular Medicine Unit, Otolaryngology Department, \\ Faculty of Medicine, Kafrelsheikh University, Kafrelsheikh, Egypt \\ 2 Audiovestibular Medicine Unit, Otolaryngology Department, \\ Faculty of Medicine, Tanta University, Tanta, Egypt \\ Address for correspondence Takwa Gabr, Audiovestibular Medicine \\ Unit, Otolaryngology Department, Faculty of Medicine, Kafrelsheikh \\ University, Kafrelsheikh 33516, Egypt \\ (e-mail: takwagabr@gmail.com; takwaadly@med.kfs.edu.eg).
}

Int Arch Otorhinolaryngol 2022;26(1):e46-e57.

\begin{abstract}
Introduction Tinnitus is the perception of sound in the absence of external sound stimulation. There is a general agreement that it is a direct consequence of irreversible and permanent cochlear damage.

Objectives The present work is designed to study the distortion product otoacoustic emissions (DPOAEs) in tinnitus patients with normal hearing in comparison with normal hearing control and to study any possible correlation between DPOAEs recording and patients' complaints.

Methods The present study included 80 subjects divided into 2 groups: Control group: consisted of 30 normal-hearing adults not complaining of tinnitus and Study group: consisted of 50 normal-hearing adults complaining of tinnitus. The methodology includes full audiological history, otoscopic examination, basic audiological evaluation, DPOAEs including both DP-gram and DPOAEs input/output functions.

Results Basic audiological evaluation showed within normal hearing sensitivity in both groups, however, with significant higher hearing thresholds in tinnitus patients at all frequency ranges. The Tinnitus Handicap Inventory Questionnaire showed mean scores of $35.2 \pm 16.9$ in the study group. The DP-gram showed higher amplitudes in the control group when compared with tinnitus patients. The DPOAEs input-output

\section{Keywords}

- tinnitus

- otoacoustic emissions

- cochlear outer hair cells functions at different frequencies $(1,2,4$ and $6 \mathrm{kHz})$ also showed higher amplitudes at all frequencies and different input levels. The slope of the $1 / 0$ function tends to be steeper in tinnitus cases.

Conclusion Patients with tinnitus might have neural dysfunction at either the level of the cochlea, as shown in reduced DPOAE levels, and changes in the normal DP-I/O function recorded in the present work.
\end{abstract}

\section{Introduction}

Tinnitus may be defined as an unwanted auditory perception of internal origin. ${ }^{1}$ The prevalence of tinnitus increases with age, peaking in the $7^{\text {th }}$ decade of life. ${ }^{2-4}$

received

July 17,2020

accepted after revision

November 8, 2020

published online

March 29, 2021
DOI https://doi.org/ 10.1055/s-0040-1722248. ISSN 1809-9777.
Tinnitus that is not associated with an identifiable sound source is assumed to be associated with damage to the auditory system anywhere between the cochlea and the auditory cortex. ${ }^{5}$ However, the majority of cases are triggered by or associated with cochlear damage. ${ }^{6,7}$ Recent

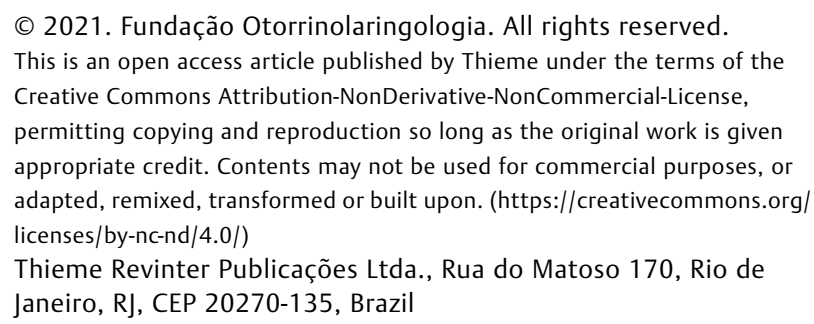


studies have shown how cochlear damage can lead to unexpected functional changes in the central auditory system that may be related to hyperacusis and tinnitus. ${ }^{8}$ Tinnitus can also cause various somatic and psychological disorders that interfere with the quality of life, including concentration difficulties or insomnia. ${ }^{9}$

As mentioned before, the cochlear function may play an important role in the generation of tinnitus perception. So, the assessment of the inner ear is important for the evaluation of tinnitus patients. Cochlear function can be tested objectively and noninvasively using otoacoustic emissions, including distortion product optoacoustic emissions (DPOAEs). ${ }^{10}$ Distortion product optoacoustic emissions amplitudes were significantly reduced in $93.3 \%$ of the normal hearing tinnitus cases. ${ }^{11}$ This suggested an altered functional state of the outer hair cells (OHCs) in the majority of the tinnitus ears with normal hearing. ${ }^{12}$ Different studies used DPOAEs to assess cochlear function in tinnitus patients; however, few studies assessed the loudness growth pattern in those cases. This will be addressed in the present work using DPOAEs input/output function (DP-I/O function).

\section{Objectives}

This is a case-controlled study that was designed to study the DP-gram and DPOAEs input/output function in tinnitus patient with normal hearing in comparison with normal hearing subjects not suffering from tinnitus. The present study also aimed at studying the possible correlation between DPOAEs recording and complaints by the patients.

\section{Method}

In the present study, we recruited 80 subjects with bilateral normal peripheral hearing to participate. They were divided into two groups:

Group 1 (control group): composed of 30 subjects free from tinnitus.

Group 2 (study group): composed of 50 subjects suffering from tinnitus.

Inclusion criteria: Subjects with bilateral normal peripheral hearing thresholds ( $\leq 25 \mathrm{dBHL}$ at all frequencies) with age range between 18 and 50 years old. All participants had no history of current external or middle ear disorders, history of noise exposure, systemic diseases or psychiatric problems

Exclusion criteria: Subjects with hearing impairment, history of ototoxic medication, chronic disorders such (as diabetes mellitus or hypertension), cervical spondylosis, history of head injury or cerebrovascular accident, psychiatric disorders or endocrinal diseases.

The present study was conducted in the Audiovestibular unit, Otolaryngology, Head and Neck Surgery Department, Kafrelsheikh University Hospitals, Egypt. Consents were obtained from all participants in the present work after explaining the test procedure. All cases were recruited from cases attending the Audiovestibular unit at Kafrelsheikh
University Hospitals. The present work was approved by the Ethical committee at the faculty of Medicine, Kafrelsheikh University Hospitals (Approval code: 17-7-2018).

All cases were submitted to:

Full history taking

Otoscopy examination

Basic audiological tests, including: air conduction pure tone audiometry along the frequency range of $250-8,000 \mathrm{~Hz}$, in addition to mid-octave frequencies $(750 \mathrm{~Hz}, 1,500 \mathrm{~Hz}$, $3,000 \mathrm{~Hz}$ and $6,000 \mathrm{~Hz}$ ) and bone conduction pure tone audiometry along the frequency range of $500-4,000 \mathrm{~Hz}$, speech audiometry (including both speech reception thresholds and word discrimination \%), immittancemetry (including tympanometry and acoustic reflexes thresholds).

Tinnitus matching for the study group including:

1. Pitch matching: It is measured by varying the frequency of a pure tone or narrow band noise so that it is matched with the pitch of the tinnitus

2. Loudness matching: The patient is instructed to raise his/her hand whenever the stimulus is equal in loudness to his/her tinnitus. Loudness is expressed in $\mathrm{dB}$. In the present study, the ascending method was used.

Arabic version of Tinnitus Handicap Inventory Questionnaire $^{13}$ to assess the psychological impact of tinnitus. This questionnaire includes 10 questions, and the patient should answer with no (score $=0)$, sometimes (score $=5$ ), or always ( score $=10$ ). At the end of the questionnaire, the total score was calculated and the psychological impact of tinnitus was calculated accordingly.

Distortion Product Otoacoustic Emissions (DPOAEs):

The stimulus composed of a pair of primary pure tones (f1 and f2) at f2/f1 frequency ratio equal to 1.22 , presented at two levels ( $\mathrm{L} 1$ and L2), where L2 is higher than L1 by $10 \mathrm{~dB}$. Two methods of DPOAEs recording were used:

3. DP-gram: in this modality, we measure the $2 \mathrm{f} 1-\mathrm{f} 2$ DPOAEs amplitudes at various $\mathrm{f} 2$ frequencies along the frequency range of $1,000-6,000 \mathrm{~Hz}$ with fixed stimulus intensities ( $\mathrm{L} 1=65 \mathrm{~dB}$ and $\mathrm{L} 2=55 \mathrm{~dB} \mathrm{SPL}$ ).

Distortion product optoacoustic emissions were considered present if the DP-signal to noise ratio (SNR) exceeded the noise floor by $>3 \mathrm{~dB}$.

4. DPOAEs Input/output function (DP-I/O): this function is recorded by measuring the DPOAE amplitude as a function of a change of stimulus level at a particular $\mathrm{f} 2$ frequency of $1,000,2,000,4,000$, and $6,000 \mathrm{~Hz}$. At each frequency, the stimulus levels started at $75 \mathrm{~dB}$ for $\mathrm{L} 1$ and $65 \mathrm{~dB}$ for $\mathrm{L} 2$ then decreased in $5 \mathrm{~dB}$ until reaching 50dB for L1 and 40dB for L2.

The collected data were organized, tabulated and statistically analyzed using IBM SPSS Statistics for Windows, version 19 (IBM Corp. Armonk, NY, USA). Qualitative data were presented as number and percentage. Quantitative data were described using minimum and maximum, mean and standard 
deviation (SD). The level of significance was adopted at $p<0.05$. The used tests were: the Chi-squared test for categorical variables, to compare between different groups, the Student t-test for normally quantitative variables to compare between two studied groups, and the Mann Whitney test for abnormally quantitative variables to compare between two studied groups, and the Spearman coefficient to correlate between two normally quantitative variables.

\section{Results}

The present study was performed from July, 2018 to January, 2020, and included 80 participants: 50 as study cases and 30 as controls, with an age range between 18 and 50 years old. The mean age of the control group was $33.5 \pm 1.3$ years old, while that of the study group was $37.3 \pm 3.3$ years old, with no significant difference between both groups $(p<0.05)$. Regarding gender, the female percentages were higher in both groups, and represented 62 and $76 \%$ in the study and control groups, respectively, with no significant difference between both groups $(p<0.05)$.

In the study group, tinnitus was found to be bilateral in $56 \%$ of the cases and unilateral in $44 \%$ of the cases (left-sided in $32 \%$ and right-sided in $12 \%$ of the cases).

The results of the basic audiologic evaluation were within normal hearing sensitivity along the frequency range of $250-8,000 \mathrm{~Hz}$, in addition to mid-octave frequencies (except at $6,000 \mathrm{~Hz}$, where it did not reach a significant level). However, there was a significant higher hearing threshold in tinnitus patients at all frequency ranges, especially in high frequency $(>2 \mathrm{kHz}$ ). The results of immittancemetry showed type A tympanograms in both ears with normal ipsilateral and contralateral acoustic reflex (AR) thresholds in both ears in both groups (-Figure 1).

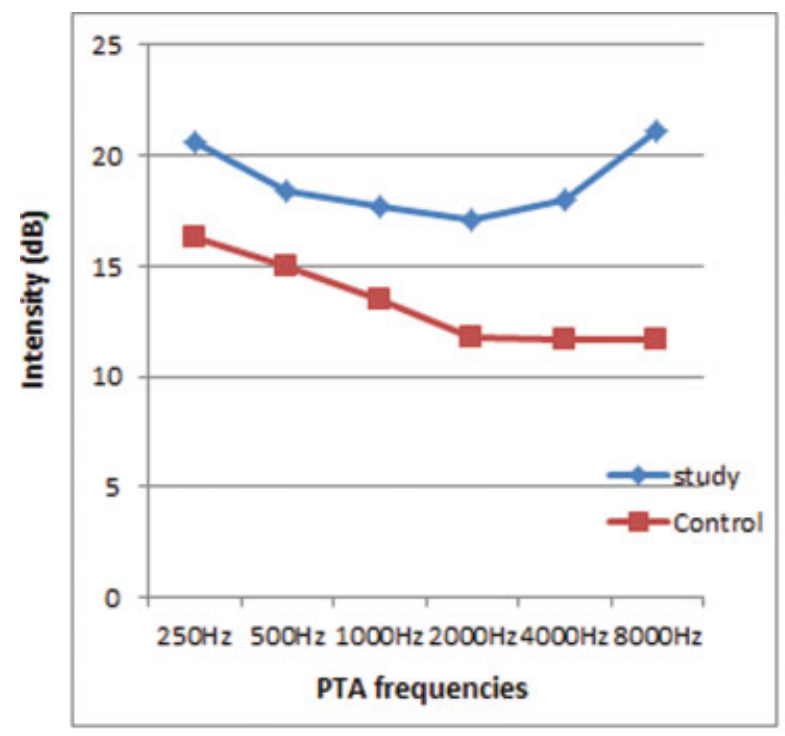

(a)
Tinnitus matching for frequency test was performed, and the results revealed that the minimum tinnitus frequency was $1 \mathrm{kHz}$, and that the maximum frequency was $8 \mathrm{kHz}$ (Median $=1$ $\mathrm{kHz} ; \mathrm{IQR}=1-4 \mathrm{KHz}$ ). In more details, the tinnitus frequency was $\geq 4 \mathrm{KHz}$ in 8 ears, at the mid frequency range $(1-3 \mathrm{KHz})$ in 10 ears, at the low frequency range $(<1 \mathrm{KHz})$ in 10 ears, and noise in 22 ears. Tinnitus matching for intensity revealed low intensity tinnitus ( $<40 \mathrm{~dB}$ ) in 25 ears ( 8 ears at $20 \mathrm{~dB}$ and 17 ears at $30 \mathrm{~dB}$ ), moderate intensity level $(40-60 \mathrm{~dB}$ ) in 21 ears ( 9 ears at $40 \mathrm{~dB}, 8$ ears at $50 \mathrm{~dB}, 4$ ears at $60 \mathrm{~dB}$ ), while 4 ears suffered from loud tinnitus $>60 \mathrm{~dB}$ ( 3 ears at $70 \mathrm{~dB}$ and one ear at $90 \mathrm{~dB}$ ).

The Arabic version of the Tinnitus Handicap Inventory Questionnaire was applied in order to assess the disability caused by tinnitus, and the results showed mean scores of $35.2 \pm 16.9$ in the study group. Thirty cases ( $60 \%$ of the total) had mild impairment, 17 cases had moderate impairment (34\%), while 3 cases (6\%) had severe impairment.

Distortion product optoacoustic emissions were recorded using two techniques. The first one is recording of DP-gram along the frequency range of $1,000-6,000 \mathrm{~Hz}$. The second technique is recording DP-I/O function. Regarding DP-gram in the right ear, the amplitudes of the DPOAEs were higher in the control group when compared with tinnitus patients at all frequencies, except $1 \mathrm{kHz}$, with the largest difference between both groups at $2 \mathrm{kHz}$ when compared with other frequencies. In the left ear, the amplitudes of DP were significantly higher in the control group as compared with tinnitus patients, with the largest difference between 2 groups at $4 \mathrm{KHz}$ for amplitudes (-Table $\mathbf{1}$ ).

The DPOAEs input-output functions were studied at different frequencies $(1,2,4$ and $6 \mathrm{kHz})$, starting at $\mathrm{L} 2 / \mathrm{L} 1$ primary levels of $75 / 65 \mathrm{~dB}$ and descending in $5 \mathrm{~dB}$ steps till reaching primary levels of $50 / 40 \mathrm{~dB}$. At each level, the amplitudes of the DPOAEs were calculated and compared

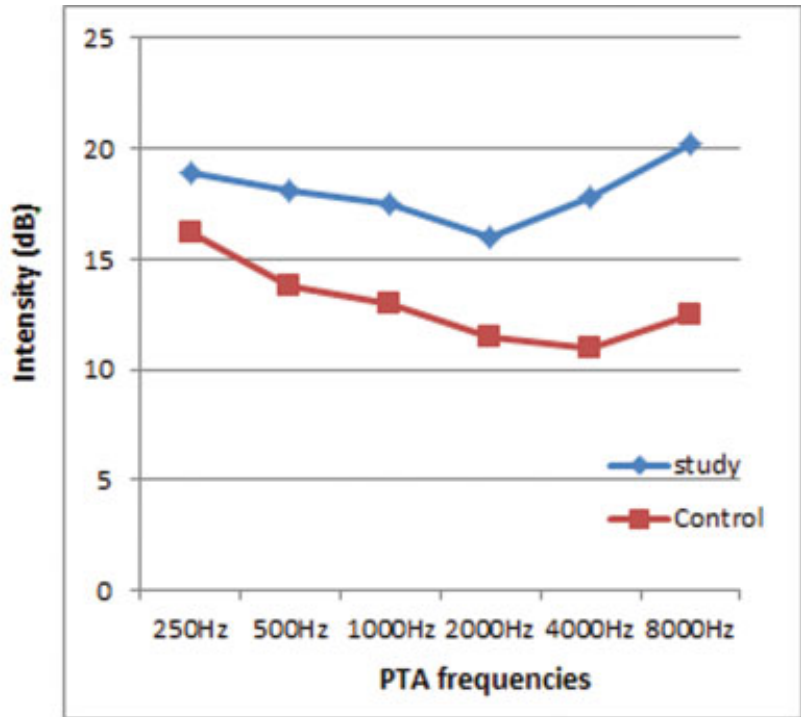

(b)

Fig. 1 Comparison of PTA thresholds between the control and study group in the right ear (a) and the left ear (b) at different frequencies. 
Table 1 Comparison of DPOAEs amplitudes between control and study groups in right and left ears

\begin{tabular}{|c|c|c|c|c|c|c|c|c|c|}
\hline \multirow{4}{*}{$\begin{array}{c}\text { DP } \\
\text { Amplitude }\end{array}$} & \multirow{4}{*}{$1 \mathrm{kHz}$} & \multirow{4}{*}{ Mean } & \multicolumn{3}{|l|}{ Right Ear } & \multicolumn{4}{|c|}{ Left Ear } \\
\hline & & & \multirow{3}{*}{$\begin{array}{l}\text { Group I } \\
9.5\end{array}$} & \multicolumn{2}{|l|}{ Group II } & \multicolumn{2}{|l|}{ Group I } & \multirow{2}{*}{$\begin{array}{l}\text { Group II } \\
11.3\end{array}$} & \\
\hline & & & & \multirow[t]{2}{*}{7.4} & \multirow{3}{*}{$\begin{array}{l}\mathrm{t}=1.020 \\
p=\mathbf{0 . 3 1 2}\end{array}$} & Median & 6.7 & & \multirow{3}{*}{$\begin{array}{l}Z_{\mathrm{mw}=2.34} \\
p=0.019\end{array}$} \\
\hline & & & & & & IQR & $1.1-10.4$ & $6.3-15.4$ & \\
\hline & & SD & 8.6 & 8.4 & & $\begin{array}{l}\text { Mean } \\
\text { rank }\end{array}$ & 32.67 & 44.58 & \\
\hline & \multirow[t]{3}{*}{$2 \mathrm{kHz}$} & Median & 13.1 & 4.6 & \multirow{3}{*}{$\begin{array}{l}Z_{\mathrm{mw}}=2.281 \\
p=0.023^{*}\end{array}$} & Median & 7.6 & 11.1 & \multirow{3}{*}{$\begin{array}{l}\mathrm{Z}_{\mathrm{mw}=2.99} \\
p=\mathbf{0 . 0 0 3}\end{array}$} \\
\hline & & IQR & $3.7-18.2$ & $2.5-11.1$ & & IQR & $3.4-10.3$ & $7.5-19.1$ & \\
\hline & & $\begin{array}{l}\text { Mean } \\
\text { rank }\end{array}$ & 40.97 & 25.03 & & $\begin{array}{l}\text { Mean } \\
\text { rank }\end{array}$ & 31.32 & 46.57 & \\
\hline & \multirow[t]{3}{*}{$4 \mathrm{kHz}$} & Median & 8.8 & 4.3 & \multirow{3}{*}{$\begin{array}{l}Z_{\mathrm{mw}}=2.146 \\
p=0.032^{*}\end{array}$} & Median & 3.0 & 9.2 & \multirow{3}{*}{$\begin{array}{l}Z_{\mathrm{mw}=2.74} \\
p=0.006\end{array}$} \\
\hline & & IQR & $3.8-13.7$ & $-3.1-9.1$ & & IQR & $-1.3-9.5$ & $3.5-13.5$ & \\
\hline & & $\begin{array}{l}\text { Mean } \\
\text { rank }\end{array}$ & 38.15 & 27.51 & & $\begin{array}{l}\text { Mean } \\
\text { rank }\end{array}$ & 31.83 & 45.82 & \\
\hline & \multirow[t]{3}{*}{$6 \mathrm{kHz}$} & Median & -2.5 & -2.8 & \multirow{3}{*}{$\begin{array}{c}Z_{\mathrm{mw}}=3.417 \\
p=0.001^{*}\end{array}$} & Median & -9.7 & -3.9 & \multirow{3}{*}{$\begin{array}{l}Z_{\mathrm{mw}=2.23} \\
p=0.026\end{array}$} \\
\hline & & IQR & $-5.8--0.2$ & $-16.6--4.9$ & & IQR & $-18.5--2.5$ & $-9.4-2.4$ & \\
\hline & & $\begin{array}{l}\text { Mean } \\
\text { rank }\end{array}$ & 37.82 & 27.81 & & $\begin{array}{l}\text { Mean } \\
\text { rank }\end{array}$ & 32.90 & 44.25 & \\
\hline
\end{tabular}

Abbreviations: DP, Distortion product; IQR, interquartile range; SD, standard deviation.

*significant at $p<0.05$, t; Independent $t$-test, $Z_{\text {mw }}$; Mann-Whitney $U$ test

between both groups in each ear. At $1 \mathrm{kHz}$, both the right and left ears showed higher DPOAEs amplitudes in the control group, which were significant only at $65 / 55 \mathrm{~dB}$ (-Table 2; - Fig. 2).

At $2 \mathrm{kHz}$, the DP-I/O function showed significant higher amplitudes at all primary levels in the right and left ears of the control group when compared with tinnitus patients. Similar results were found in the left ear at $4 \mathrm{kHz}$, while the right ear showed significant higher amplitudes at high input levels only in the same frequency $(75 / 65,70 / 60,65 / 55)$ (-Tables 3, 4; - Figures 3 and 4).

At $6 \mathrm{kHz}$, the DP-I/O function showed significant higher amplitude at all primary levels in the right ear of the control group when compared with tinnitus patients, except at $50 / 40$, which did not reach a significant level. In the left ear, there were significantly higher amplitudes only at high input levels $(75 / 65,70 / 60,65 / 55)$ (-Table 5 and -Figs. 5, 6).

To quantify the DP-growth function, the slope(s) of the $\mathrm{I} / \mathrm{O}$ functions were calculated at different frequencies between 40-65 dB SPL level of L2 and compared between both groups. In the control group, the $\mathrm{I} / \mathrm{O}$ function at 1 and $2 \mathrm{KHz}$ tends to be more flattened at $\mathrm{L} 2$ level $\geq 55 \mathrm{dBSPL}$, while at 4 and $6 \mathrm{kHz}$, the $\mathrm{I} / \mathrm{O}$ function tends to be steeper along all $\mathrm{L} 2$ levels. In the study group, the steeper $\mathrm{I} / \mathrm{O}$ function tends to be preserved along all $\mathrm{L} 2$ levels at all frequencies, except at $1 \mathrm{kHz}$, where it tends to be flatter ( - Figures $\mathbf{6}$ and $\mathbf{7}$ ).

In the present work, we studied the possible correlation between tinnitus questionnaire results and tinnitus frequency, tinnitus intensity and DP-gram amplitudes along different frequencies $(1-6 \mathrm{kHz})$. The results showed no correlation between any of these parameters $(p>0.05)$.

\section{Discussion}

Tinnitus is a common disorder with hearing of unpleasant sounds; however, it is poorly understood. The expected increase in knowledge about the mechanism involved in tinnitus and potential treatment strategies will help in providing relief to this annoying disease. There are several hypotheses regarding the mechanisms of tinnitus generation. Most of the authors consider the origin of tinnitus as cochlear, such as lesions of the hair cells after acoustic trauma, presbycusis or sudden hearing loss. In 1990, Jastreboff $^{14}$ had proposed that tinnitus probably starts in the cochlea and then the abnormal activity is generated in the central pathways that prolong the symptoms.

In the present work, we recruited 80 subjects to participate: 30 subjects ( 23 females and 7 males) constituted the control group, and 50 subjects with normal hearing and suffering from tinnitus constituted the study group (31 females and 19 males). The comparison between both groups showed no significant difference regarding age or gender $(p>0.05)$.

Studying the laterality of tinnitus in the present study showed that tinnitus was bilateral in $56 \%$ of the cases, leftsided in $32 \%$ of the cases, and right-sided in $12 \%$ of the cases. This is consistent with other studies ${ }^{15,16}$ that reported a similar higher percentage of left-sided tinnitus than rightsided tinnitus. This could be due to anatomical and physiological differences in the structures of the right and left central nervous system (CNS). For example, the left ear seems to be more susceptible to a wide range of cochlear insults, such as noise and ototoxic drugs. ${ }^{15,17,18}$ 


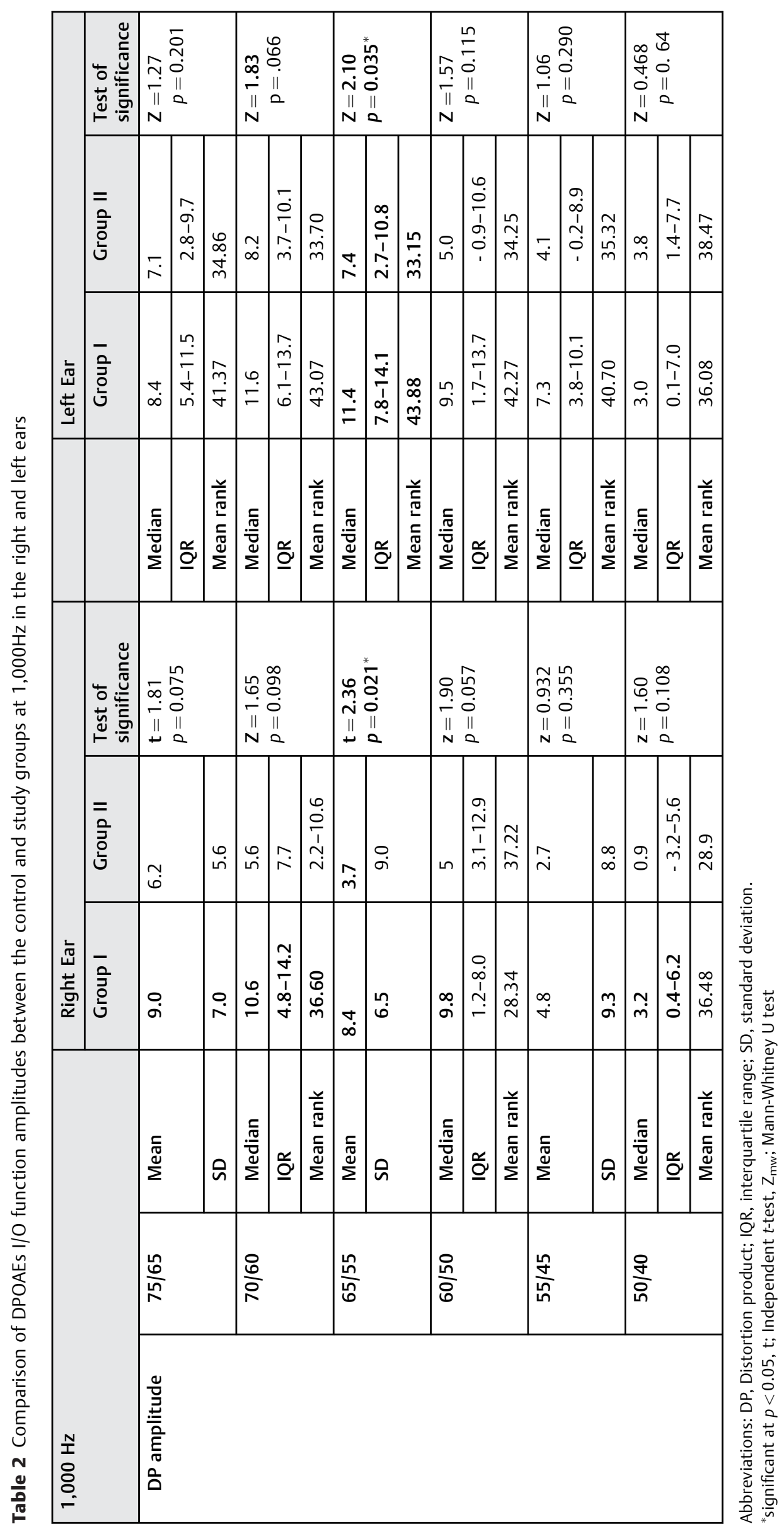




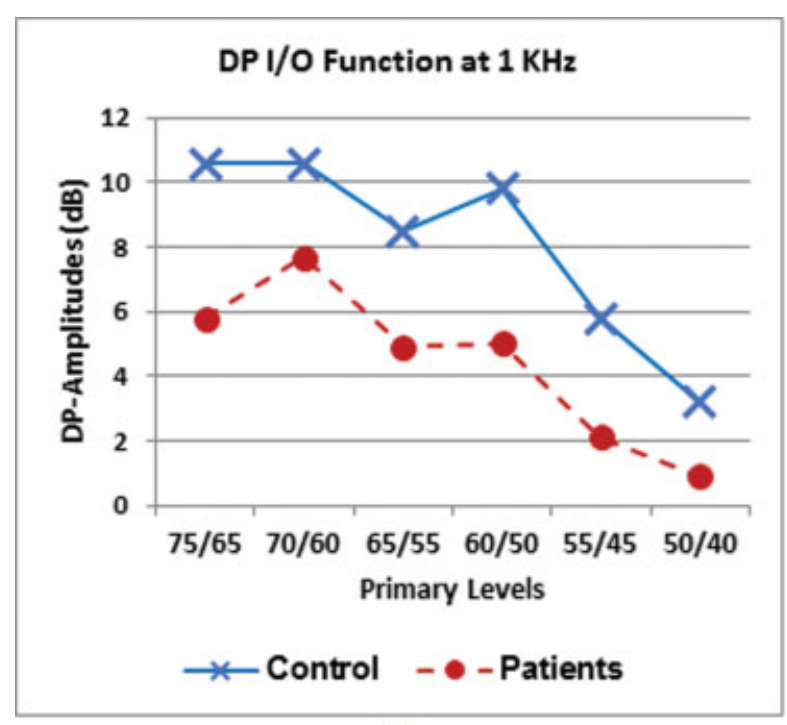

(a)

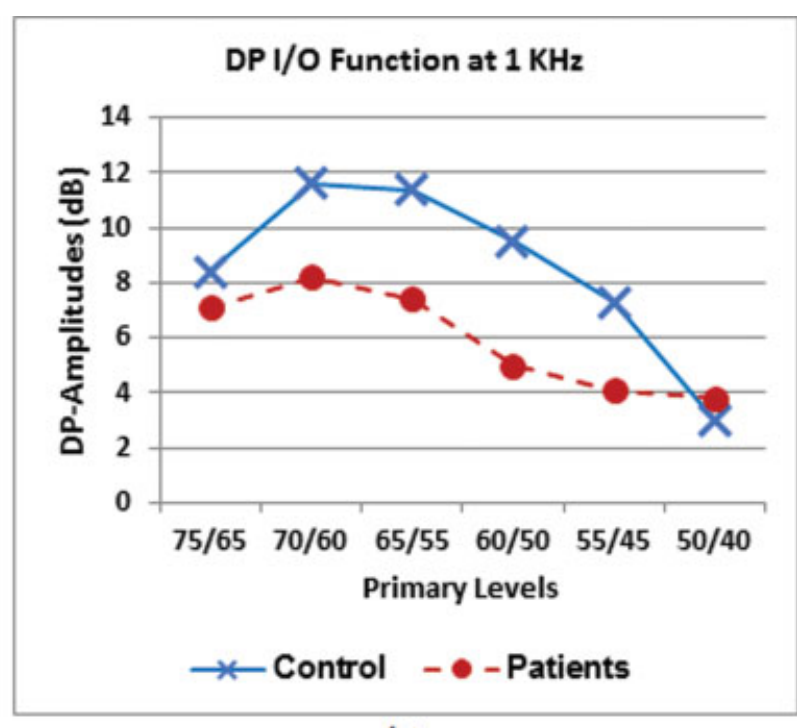

(b)

Fig. 2 Comparison of DPOAEs I/O function amplitudes between the control and study groups in the right ear (a) and left ear (b) at $1 \mathrm{kHz}$.

Despite the presence of normal pure tone audiometry (PTA) results in tinnitus patients in the present study, their hearing thresholds were significantly elevated when compared with the control group. This suggested that normal PTA does not necessarily exclude cochlear damage. Kujawa et al. ${ }^{19}$ supported the possibility of the presence of a subclinical hearing loss with normal hearing thresholds, or what is called "missing hearing loss" ${ }^{20}$. Additionally, tinnitus may be a primary symptom of diseases that are only diagnosed after the occurrence of hearing loss. ${ }^{21}$

$n$ the present study, the possibility of cochlear dysfunction as a cause of tinnitus generation was studied using DPOAEs recording in tinnitus patients with normal hearing. The selection of DPOAEs was based on its current use as an efficient tool for the objective evaluation of the inner ear function, especially of the outer hair cells of the cochlea. ${ }^{22}$ The DP-gram was recorded in both groups at 1,2, 4 and $6 \mathrm{kHz}$. The results in the right ear showed significantly higher DPOAEs amplitudes in the control group at all frequencies, except at $1 \mathrm{kHz}$. In the left ear, the amplitude of the DP was significantly higher in the control group when compared with tinnitus patients. These findings suggest the possibility of subtle damage to the OHCs in tinnitus patients, which can be detected early with DPOAEs even before it is manifested as a shift in audiometric thresholds. ${ }^{23}$ Some studies suggested that the basal region of the cochlea may contribute to some extent to DPOAEs measured at lower frequencies. Traditional audiometric data usually do not include higher frequencies ( $>8$ or $10 \mathrm{kHz}$ ). Therefore, normal conventional audiometry does not exclude higher frequencies affection. Additionally, OHC impairment in the most basal cochlear region may result in reduced contribution to more apically generated DPOAEs. ${ }^{24,25}$ Similar data were reported by Clark et al., ${ }^{26}$ who found that OHCs damage of $\sim 20 \%$ might not be detected in the behavioral threshold measures. Another hypothesis suggested the presence of $\mathrm{OHC}$ impairment along with other subclinical pathologies, such as loss of normally high-thresh- old spiral ganglion cells with subsequent generation of tinnitus. $^{27}$

Results of DP-growth function showed higher DPOAEs amplitudes in control cases, which were significant at the majority of frequencies and intensity levels (-Tables 3-5; - Figures 3-7). Regarding the slope of the DP-growth function, there was a tendency of a steeper slope of the I/O functions mainly at high frequencies ( 4 and $6 \mathrm{kHz}$ ) in both groups. At lower frequencies, the $\mathrm{I} / \mathrm{O}$ function tends to be more compressive, especially at high input levels ( 1 and $2 \mathrm{kHz}$ ), which were more evident in normal cases (-Figure 7). These findings were consistent with earlier observations of differences in cochlear processing at the base, compared with the apex. Fibers with high characteristic frequency (CF) innervating hair cells at the cochlear base had sharper tuning (with long low-frequency tails where the threshold remained relatively constant regardless of the frequency) compared with low-CF fibers innervating more apically located hair cells (with more symmetrical tuning, and low-frequency). ${ }^{28}$ On using DPOAE I/O functions in human ears with normal hearing, these functions are characterized by a linear segment as the response emerges from the noise floor, followed by a compressive region over which the output is no longer linearly related to the input. ${ }^{29}$

The sharp slope of the $\mathrm{I} / \mathrm{O}$ function in tinnitus patients, especially at high frequencies, suggested diminished sensitivity and tuning of the cochlear amplifier, which alters the auditory processing that already occurs at the cochlear level. The linear growth function seen in tinnitus patients also might suggest the possibility of deficient efferent inhibition. This, in turn, might affect cortical activity, leading to hyperactivity in the OHCs. ${ }^{30}$ It could be also due loss of the normal loudness growth, where auditory sensitivity might be rescaled as a function of the mean level of auditory sensory inputs. ${ }^{31}$ Additionally, tinnitus is usually associated with increased central gain as a result of reduction of auditory input, even when hearing loss is still not detectable on the audiogram. $^{32}$ 


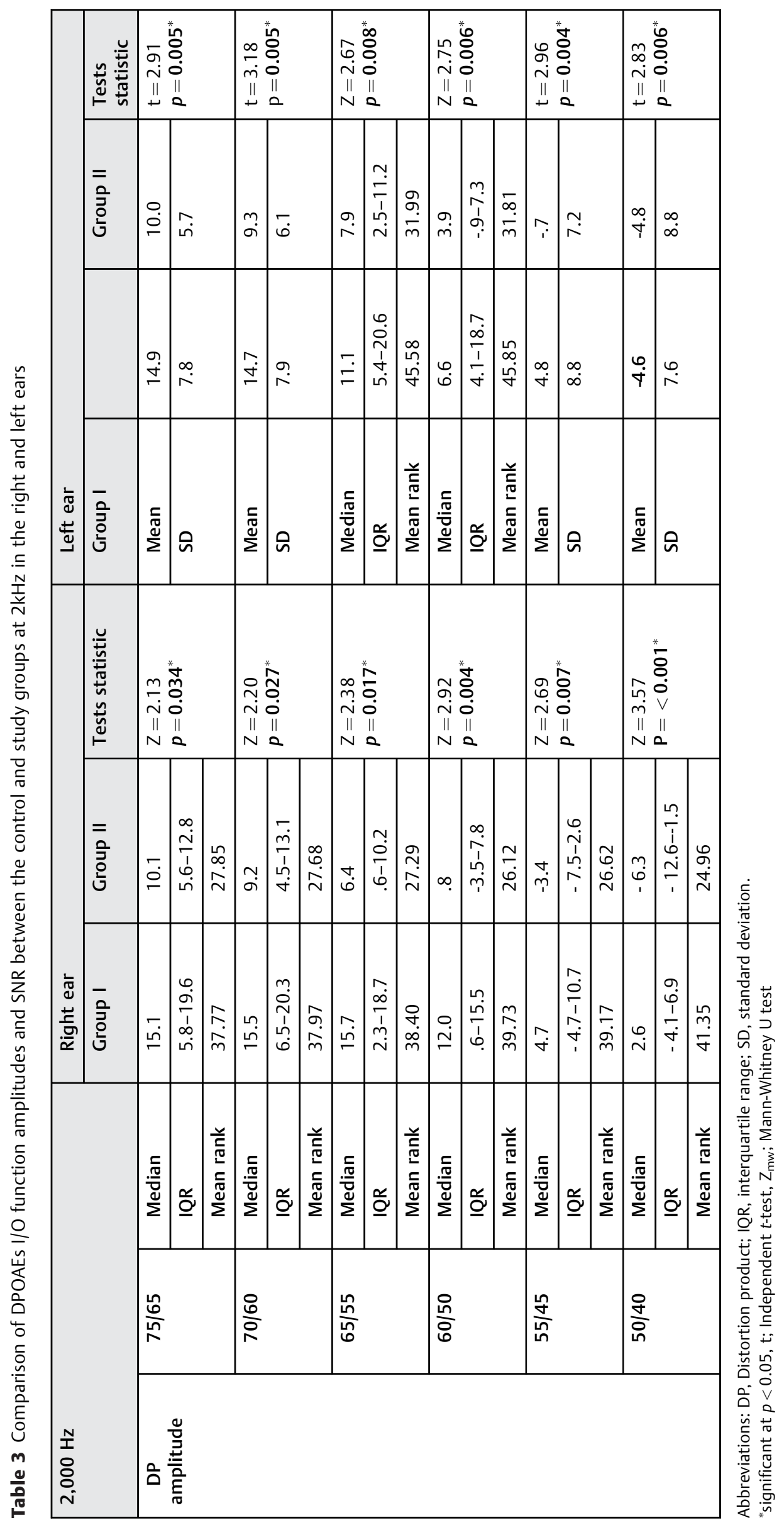



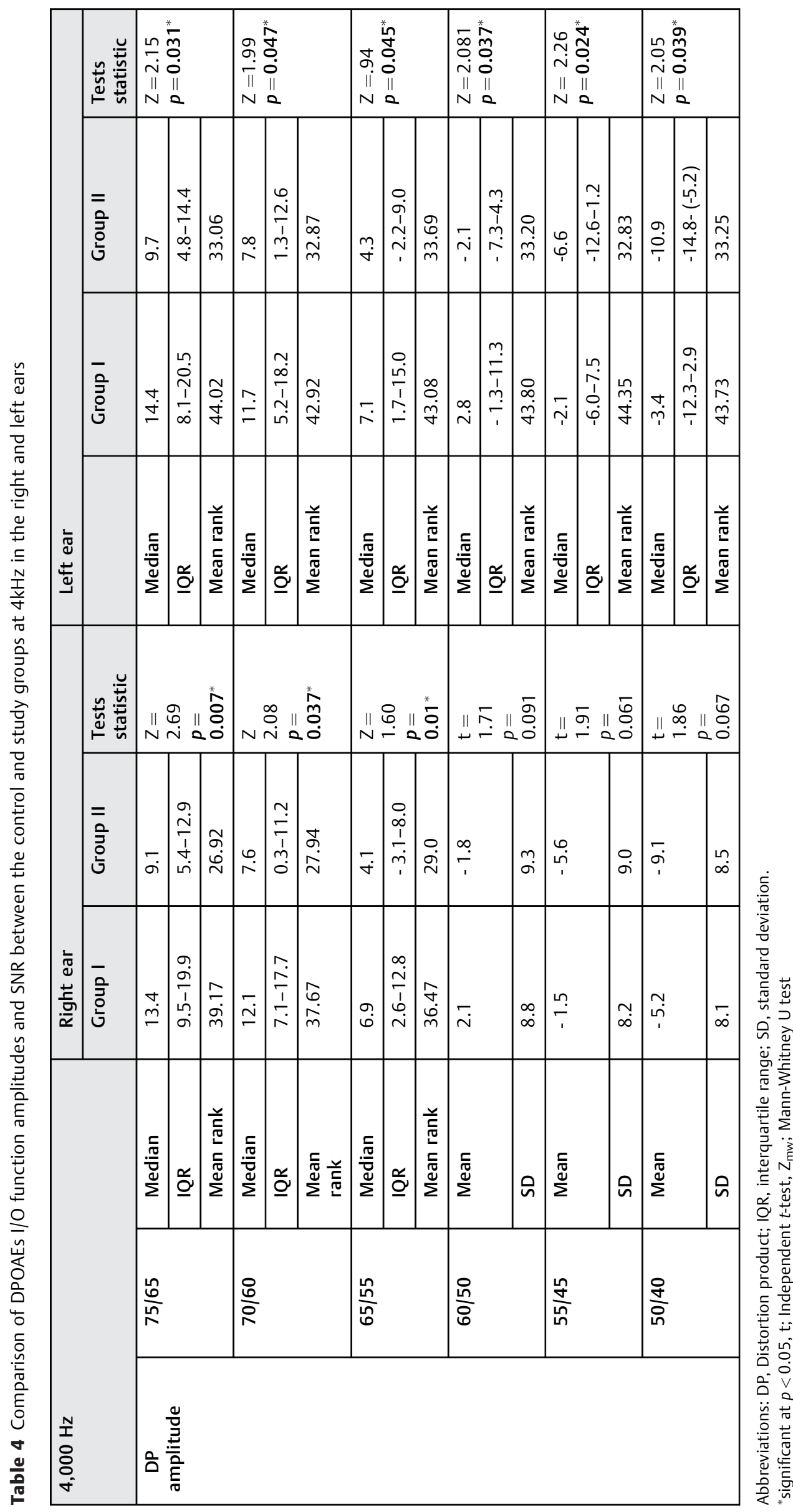
54 Distortion Product Otoacoustic Emissions (DPOAEs) In Tinnitus Patients Alshabory et al.

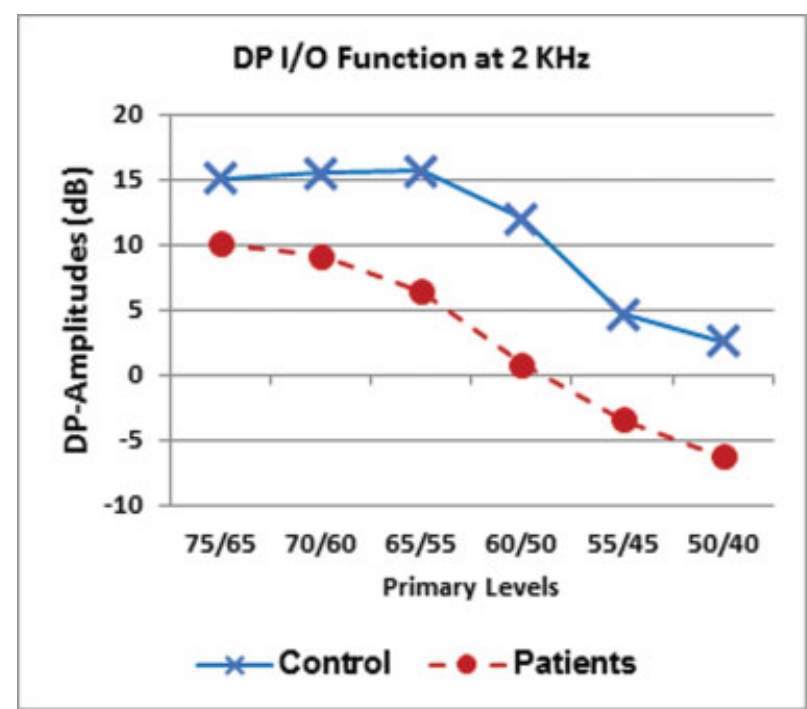

(a)

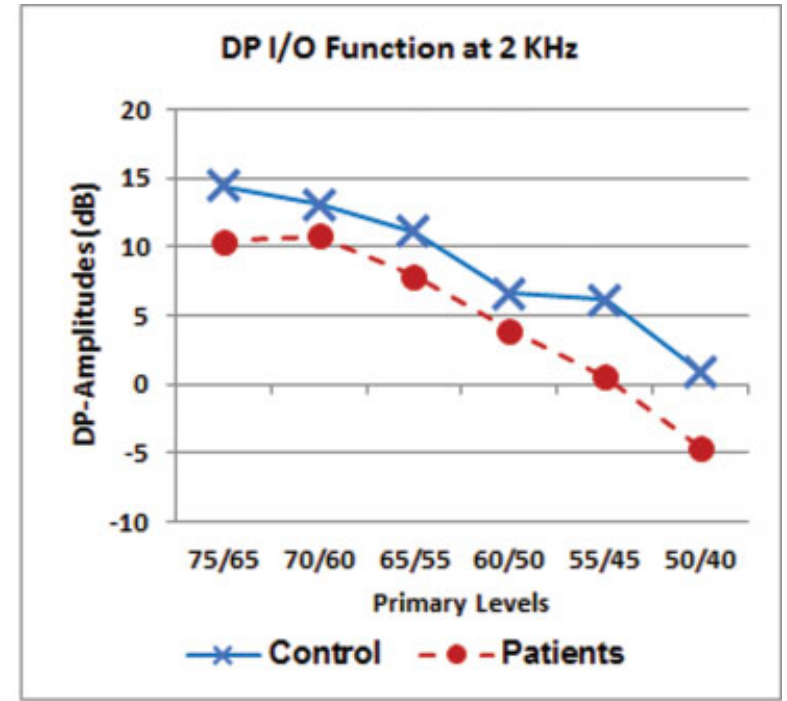

(b)

Fig. 3 Comparison of DPOAEs $1 / O$ function amplitudes between the control and study groups in the right ear (a) and left ear (b) at $2 \mathrm{kHz}$.

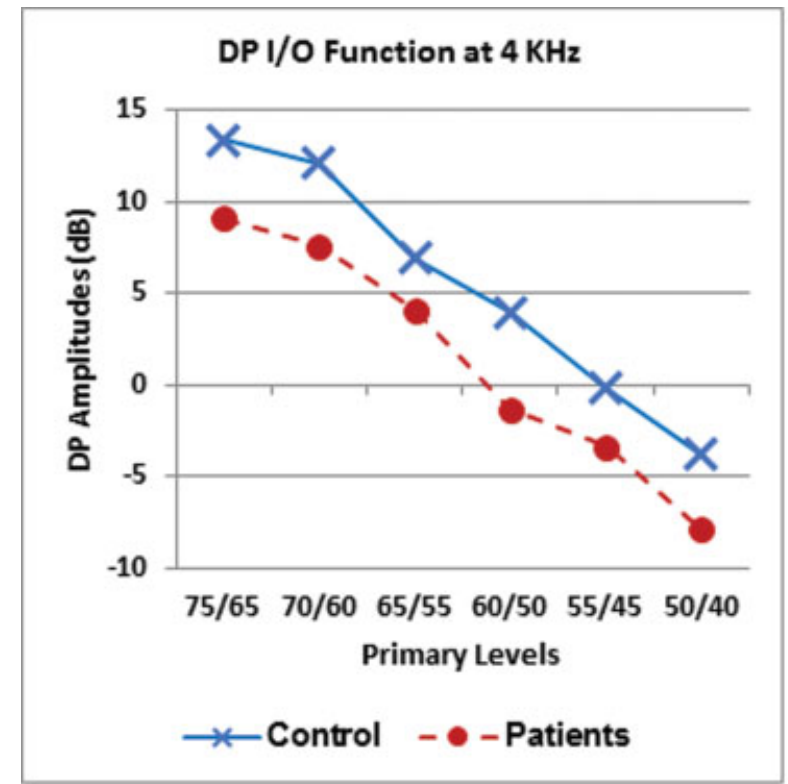

(a)

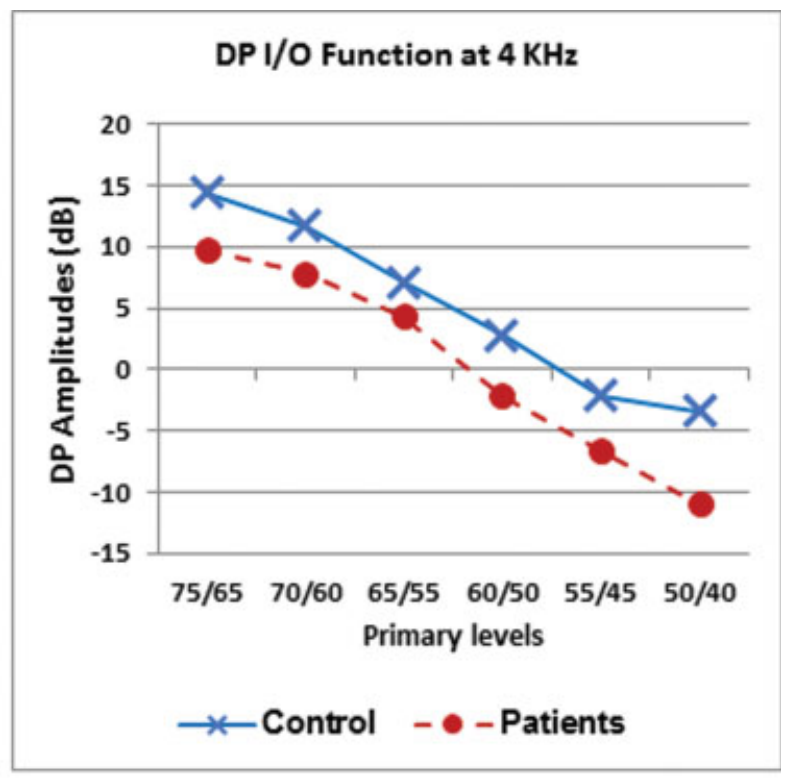

(b)

Fig. 4 Comparison of DPOAEs I/O function amplitudes between the control and study groups in the right ear (a) and left ear (b) at $4 \mathrm{kHz}$.

\section{Conclusion}

In conclusion, patients with tinnitus might have neural dysfunction at either the level of the cochlea, of the auditory nerve, or of the brainstem. In the present work, we indirectly assessed the integrity of the afferent auditory pathway by using DPOAEs in tinnitus cases with normal hearing. The results showed that those affected by tinnitus show reduced
OHC activity, as detected by reduced DPOAE levels and change in the normal DP-I/O function, which may manifest as tinnitus even before there is a shift in the hearing threshold.

Conflict of Interests

The authors have no conflict of interests to declare. 


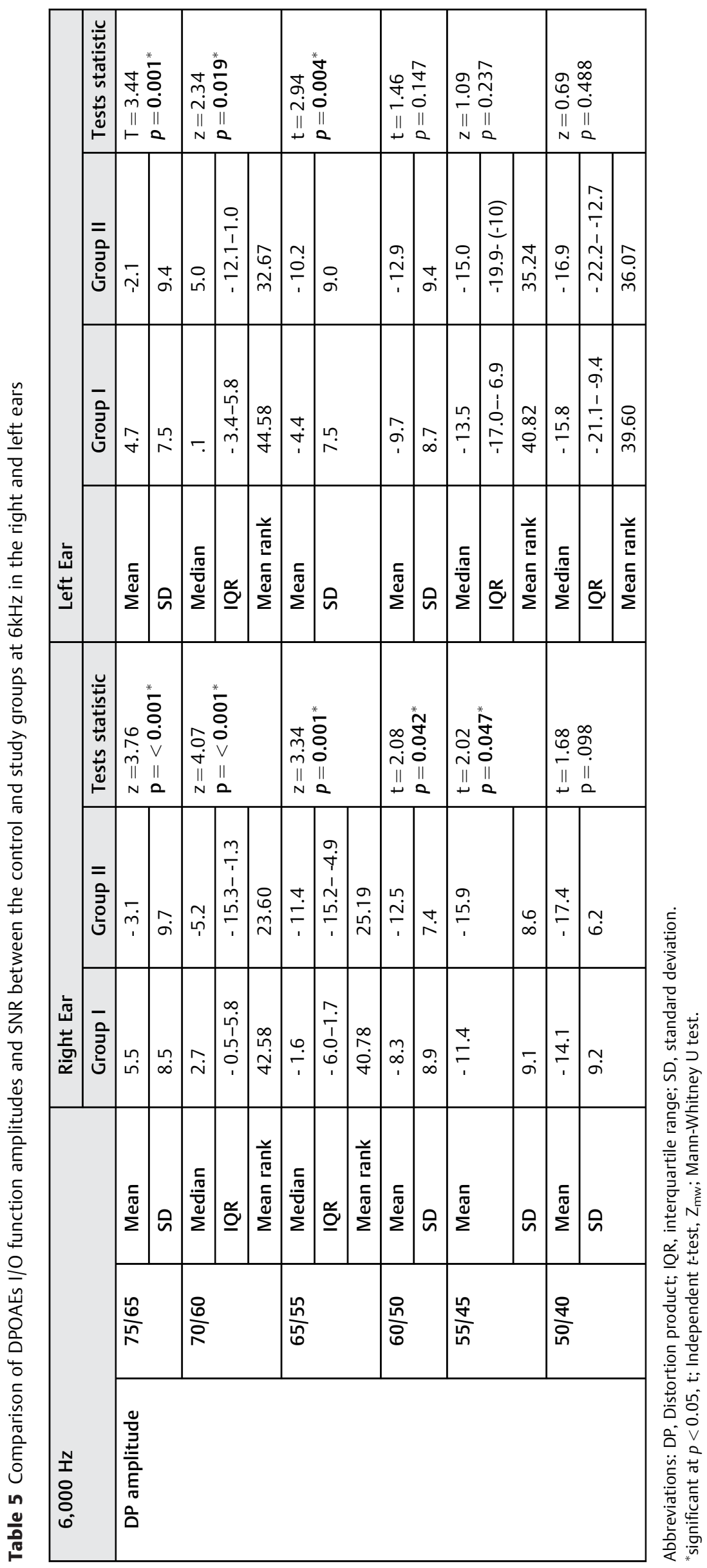




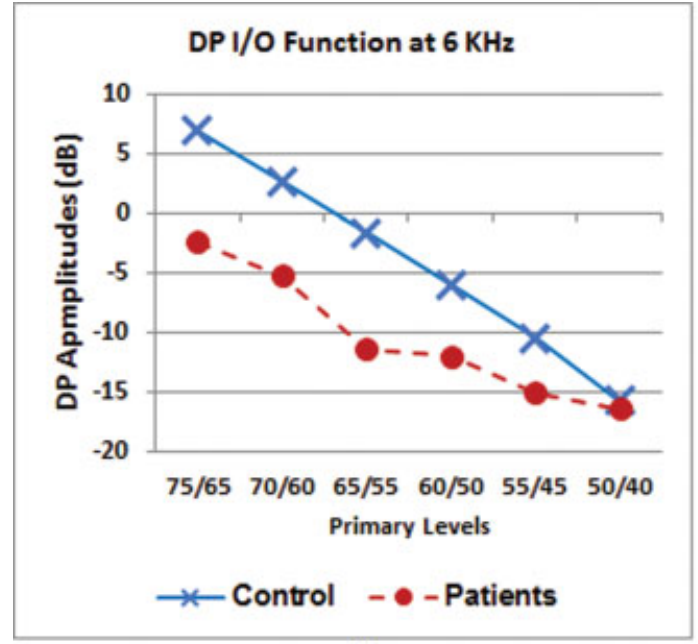

(a)

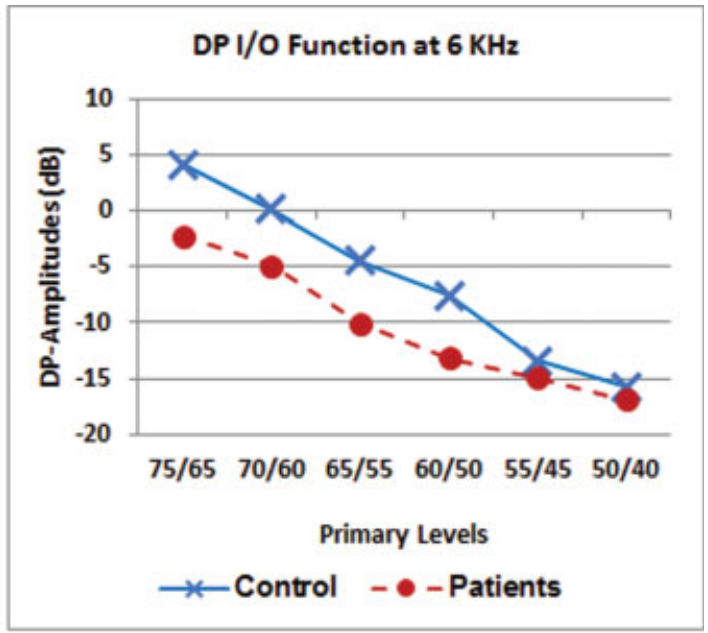

(b)

Fig. 5 Comparison of DPOAEs I/O function amplitudes between the control and study groups in right ear (a) and left ear (b) at $6 \mathrm{kHz}$.

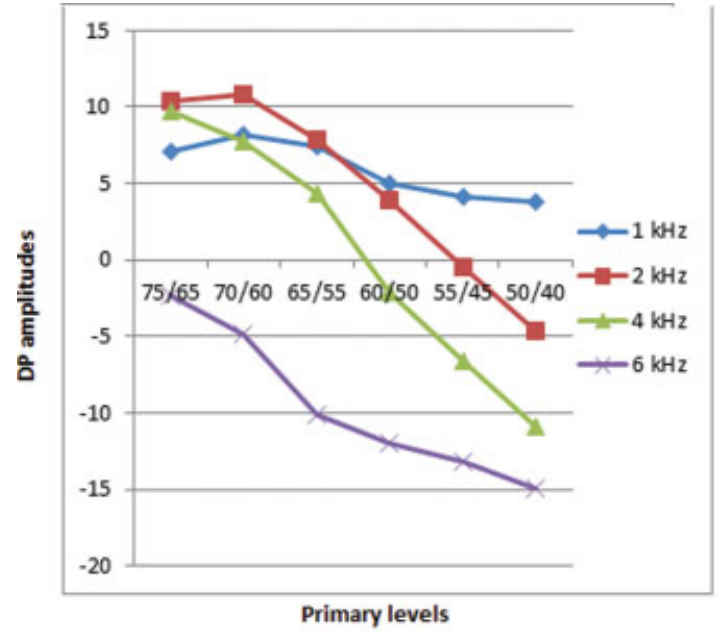

(a)

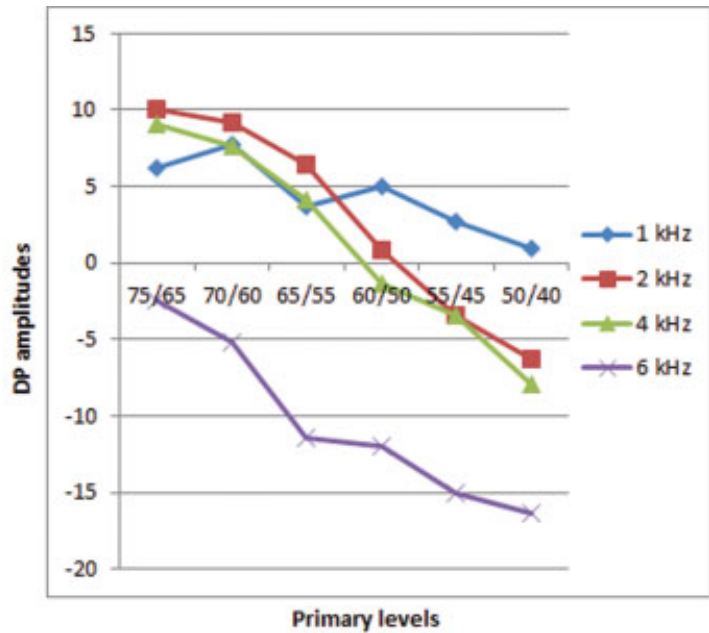

(b)

Fig. 6 DP-I/O function at different frequencies in the right ear (a) and left ear (b) of the control group.

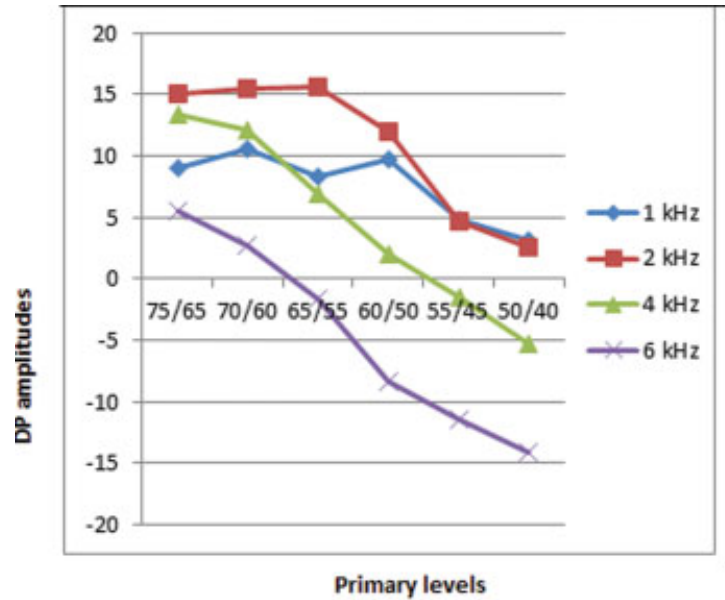

(a)

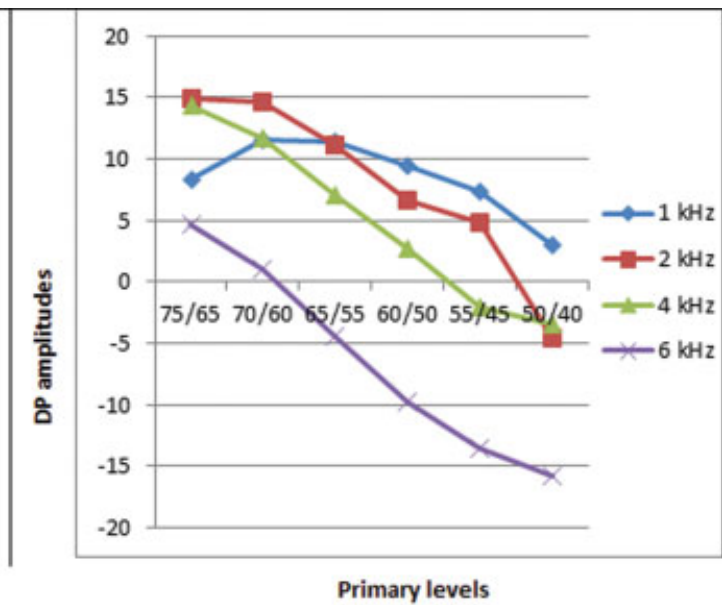

(b)

Fig. 7 DP-I/O function at different frequencies in the right ear (a) and left ear (b) of the study group 


\section{References}

1 Crummer RW, Hassan GA. Diagnostic approach to tinnitus. Am Fam Physician 2004;69(01):120-126

2 Nondahl DM, Cruickshanks KJ, Wiley TL, Klein R, Klein BE, Tweed TS. Prevalence and 5-year incidence of tinnitus among older adults: the epidemiology of hearing loss study. J Am Acad Audiol 2002;13(06):323-331

3 Shargorodsky J, Curhan GC, Farwell WR. Prevalence and characteristics of tinnitus among US adults. Am J Med 2010;123(08): 711-718

4 Park KH, Lee SH, Koo JW, et al. Prevalence and associated factors of tinnitus: data from the Korean National Health and Nutrition Examination Survey 2009-2011. J Epidemiol 2014;24(05): 417-426

5 Roberts LE. Neural synchrony and neural plasticity in tinnitus. In: Møller AR, Langguth B, DeRidder D, Kleinjung T, editors. Textbook of Tinnitus. New York: Springer; 2011:103-112

6 Hazell J. Incidence, classification, and models of tinnitus. In: Ludman H, Wright T, editors. Diseases of the Ear. London: Arnold; 1998:185-195

7 Rodriguez-Casero MV, Mandelstam S, Kornberg AJ, Berkowitz RG. Acute tinnitus and hearing loss as the initial symptom of multiple sclerosis in a child. Int J Pediatr Otorhinolaryngol 2005;69(01): 123-126

8 Henry JA, Roberts LE, Caspary DM, Theodoroff SM, Salvi RJ. Underlying mechanisms of tinnitus: review and clinical implications. J Am Acad Audiol 2014;25(01):5-22, quiz 126

9 Claussen CF, Franz B. Contemporary and practical neurootology. Germany2006;18:298-299

10 Weisz N, Müller S, Schlee W, Dohrmann K, Hartmann T, Elbert T. The neural code of auditory phantom perception. J Neurosci 2007; 27(06):1479-1484

11 Shiomi Y, Tsuji J, Naito Y, Fujiki N, Yamamoto N. Characteristics of DPOAE audiogram in tinnitus patients. Hear Res 1997;108(1-2):83-88

12 Bartnik G, Hawley ML, Rogowski M, et al. Distortion product otoacoustic emission levels and Input/Output-Growth functions in normal-hearing individuals with tinnitus and/or hyperacusis. Semin Hear 2007;28:303-318

13 Newman CW, Jacobson GP, Spitzer JB. Development of the tinnitus handicap inventory. Arch Otolaryngol Head Neck Surg 1996;122 (02):143-148

14 Jastreboff PJ. Phantom auditory perception (tinnitus): mechanisms of generation and perception. Neurosci Res 1990;8(04): 221-254

15 Meikle M, Taylor-Walsh E. Characteristics of tinnitus and related observations in over 1800 tinnitus clinic patients. J Laryngol Otol Suppl 1984;9:17-21

16 Davis A, Rafaie EA. Epidemiology of tinnitus. In: Tyler R, editor. Tinnitus Handbook. New York: Thomson Learning; 2000:1-23

17 Kannan PM, Lipscomb DM. Letter: Bilateral hearing asymmetry in a large population. J Acoust Soc Am 1974;55(05):1092-1094
18 Schmidt CM, Knief A, Lagosch AK, Deuster D, am ZehnhoffDinnesen A. Left-right asymmetry in hearing loss following cisplatin therapy in children-the left ear is slightly but significantly more affected. Ear Hear 2008;29(06):830-837

19 Kujawa SG, Liberman MC. Adding insult to injury: cochlear nerve degeneration after "temporary" noise-induced hearing loss. J Neurosci 2009;29(45):14077-14085

20 Xiong B, Liu Z, Liu Q, et al. Missed hearing loss in tinnitus patients with normal audiograms. Hear Res 2019;384:107826

21 Ishak WS, Zhao F, Rajenderkumar D, Arif M. Measurement of subtle auditory deficit in tinnitus patients with normal audiometric thresholds using evoked otoacoustic emissions and threshold equalizing noise tests. Int Tinnitus J 2013;18(01):35-44

22 Blinowska KJ, Fernandez BR. The application of wavelet transform and matching pursuit to the time-varying EEG signals. Intelligent Engineering Systems through Artificial Neural Networks. ASME Press. 1994;4:535-540

23 Ami M, Abdullah A, Awang MA, Liyab B, Saim L. Relation of distortion product otoacoustic emission with tinnitus. Laryngoscope 2008;118(04):712-717

24 Arnold DJ, Lonsbury-Martin BL, Martin GK. High-frequency hearing influences lower-frequency distortion-product otoacoustic emissions. Arch Otolaryngol Head Neck Surg 1999;125(02): 215-222

25 Dreisbach LE, Torre P III, Kramer SJ, Kopke R, Jackson R, Balough B. Influence of ultrahigh-frequency hearing thresholds on distortion-product otoacoustic emission levels at conventional frequencies. J Am Acad Audiol 2008;19(04):325-336

26 Clark WW, Kim DO, Zurek PM, Bohne BA. Spontaneous otoacoustic emissions in chinchilla ear canals: correlation with histopathology and suppression by external tones. Hear Res 1984;16(03): 299-314

27 Fabijańska A, Smurzyński J, Hatzopoulos S, et al. The relationship between distortion product otoacoustic emissions and extended high-frequency audiometry in tinnitus patients. Part 1: normally hearing patients with unilateral tinnitus. Med Sci Monit 2012;18 (12):CR765-CR770

28 Kiang NY-S, Moxon EC. Tails of tuning curves of auditory-nerve fibers. J Acoust Soc Am 1974;55(03):620-630

29 Gorga MP, Neely ST, Dierking DM, et al. Low-frequency and highfrequency cochlear nonlinearity in humans. J Acoust Soc Am 2007;122(03):1671

30 Hesse $G$, Schaaf $H$, Laubert A. Specific findings in distortion product otoacoustic emissions and growth functions with chronic tinnitus. Int Tinnitus J 2005;11(01):6-13

31 Munro KJ, Blount J. Adaptive plasticity in brainstem of adult listeners following earplug-induced deprivation. J Acoust Soc Am 2009;126(02):568-571

32 Schaette R, McAlpine D. Tinnitus with a normal audiogram: physiological evidence for hidden hearing loss and computational model. J Neurosci 2011;31(38):13452-13457 